A partir deste número, a seção "Resenhas de artigos" da Revista Latinoamericana de Psicopatologia Fundamental passará a ser realizada pelo Laboratório de Psicopatologia Fundamental da UNICAMP, sob a coordenação do prof. Dr. Mário Eduardo Costa Pereira, diretor daquele laboratório.

"Placebo controls: no news is good news"

Kahn et alli.

Archives of General Psychiatry, April 2000, v. 57, $\mathrm{n}^{\circ} 4$.

Resenhado por: Mario Eduardo Costa Pereira

\title{
Archives of General Psychiatry discute o problema do efeito placebo em pesquisas com psicofármacos no tratamento da depressão
}

Um interessante artigo de Kahn et alli., publicado na edição de abril do Archives of General Psychiatry, relança o debate sobre o efeito placebo na pesquisa e na clínica da depressão.

O trabalho visa fornecer subsídios para o debate quanto à pertinência ética dos estudos psicofarmacológicos que comparam as drogas ativas com placebo no tratamento da depressão. Este constitui o perfil experimental exigido pelo FDA americano para que uma nova droga possa ser lançada no mercado. Ou seja, para que uma nova substância antidepressiva possa ser autorizada para a comercialização por aquele 
poderoso órgão governamental, ela deve, antes, ser submetida a uma avaliação experimental padronizada de sua eficácia, comparando seus efeitos clínicos com os provocados por placebo em pacientes com o diagnóstico de depressão em estudos duplo-cegos (nem o paciente, nem o pesquisador sabem se a cápsula contendo a medicação contém a substância ativa a ser testada ou placebo, sendo a alocação dos pacientes aos grupos "placebo" ou "droga testada” realizada de forma aleatória).

Este tipo de estudo tem sido vivamente criticado por uma parcela importante de pesquisadores psiquiátricos. Segundo eles, não há mais sentido em se submeter os pacientes deprimidos ao risco de serem tratados com placebo durante os testes, pois as novas drogas poderiam ser testadas em relação a outras substâncias antidepressivas de eficácia já comprovada. Trata-se, pois, antes de tudo, de uma objeção de natureza ética. Contudo, os estudos tipo placebo $x$ controle já são utilizados há muitos anos e constituem a forma mais tradicional de avaliação clínica de uma nova droga.

Para auxiliar numa tomada de posição, o FDA solicitou a Kahn e sua equipe que efetuassem uma revisão sistemática dos documentos das pesquisas que testaram sete novas drogas antidepressivas aprovadas entre 1987 e 1997.

Em sua revisão desses estudos duplo-cegos, Kahn não encontra qualquer resultado surpreendente: em 43 dos 45 estudos disponíveis, os pacientes que receberam placebo tiveram melhora clínica significativa ao longo do período de testes, embora não tão intensa quanto as drogas testadas. Em dois estudos, o placebo mostrou-se mais eficaz do que a substância ativa. Na maior parte dos trabalhos, as diferenças de intensidade de melhora clínica foi praticamente irrelevante.

De outra parte, quando examinou-se tentativas de suicídio e suicídios, demonstrou-se que estes são menos freqüentes entre pacientes que receberam placebo do que entre aqueles que receberam a substância ativa, embora este achado deva ser interpretado com cautela devido a dificuldades técnicas.

Globalmente, concluiu-se que, com os dados disponíveis, os estudos utilizando não acrescentam um risco considerável aos pacientes implicados no teste e demonstram que um grau importante de melhora espontânea daqueles utilizando placebo, por vezes atingindo níveis indistinguíveis dos que usaram a droga ativa.

Permanece, pois, colocada a necessidade desse tipo de estudo e o mistério clínico do efeito placebo. 
"The central fobic position: a new formulation of the Free Association Method" André Green International Journal of Psychoanalysis, 81, 2000, part 3 (obtido pela Internet: www.ijpa.org) Resenhado por: Joyce M. G. Freire

\section{International Journal of Psychoanalysis publica artigo de André G reen sobre a "Posição Central Fóbica"}

Em sua primeira edição de 2000, o International Journal of Psychoanalysis publica uma artigo de André Green, intitulado "The central fobic position: a new formulation of the free association method”, no qual traz algumas contribuições inovadoras à metapsicologia e à clínica psicanalítica.

Neste artigo, André Green traz algumas reflexões iluminadoras a respeito do tratamento com pacientes em estados-limites ou fronteiriços. Há muito, em sua escuta analítica, deparava-se com certas situações clínicas face a alguns pacientes, nas quais a associação livre era interrompida; como se tratava de pacientes neuróticos, tais interrupções eram atribuídas, como comumente acontece, ao processo de recalcamento cujo fim é manter distantes os desejos proibidos.

Alguns pacientes, porém - em especial, aquele que é apresentado minuciosamente em seu artigo e que dá sustentação à sua tese - em certos momentos do tratamento apresentavam interrupções semelhantes sem que, no entanto, estas pudessem ser elucidadas pela mesma compreensão psicanalítica tradicional. Gabriel, seu paciente, queixava-se de constante ansiedade e trazia uma história de vida confusa e caótica. Sua fala nebulosa, contrariando a idéia de um afrouxamento de associações, conduz Green a pensar em um excesso de associação em potencial (potential excess of associations) do qual se protegia apresentando uma fala confusa; temia adoecer fisicamente ou enlouquecer.

A partir de suas observações, Green traz algumas considerações metapsicológicas que nos ajudam a pensar a clínica de pacientes que estão, literalmente, no limite de si mesmos; atribui à peculiar forma de pensar e de se expressar desses pacientes a um modo de funcionamento psíquico a que denomina posição fóbica 
central; esse modo de funcionamento fóbico não circunscreve um sintoma isolado, senão que diz respeito muito mais a uma posição fóbica durante as sessões portanto, na transferência - quanto a certos temas da vida desses pacientes, os quais ecoam uns sobre os outros, criando o risco de uma desintegração catastrófica.

A negatividade de Gabriel face a certos temas conduz Green a pensar na metapsicologia da posição central fóbica em relação à negativa (Freud, 1925) - "não, isto não sou eu” - e, a partir daí, situá-la em relação à foraclusão (Freud, 1914) sem, com isto, confiná-la na psicose -, pois, em certos momentos, ocorre um nãoreconhecimento de si mesmo que beira a alucinação.

Em sua conclusão, o autor tece algumas importantes considerações sobre a temporalidade e o superego desses pacientes em relação a situações edípicas e préedípicas.

“The early origins of autism”

P. Rodier

Scientific American, February 2000, 40-45.

Resenhado por: Viviane Vianna de Andrade

\section{Uma perspectiva multifatorial sobre a origem do autismo}

A Scientific American, em recente artigo de revisão, revelou surpreendentes descobertas sobre o autismo, que desde sua primeira descrição, em 1943, tem instigado cientistas a se aprofundarem nas pesquisas sobre esta complexa desordem de comportamento.

O trabalho considerou como categorias de diagnóstico do autismo as falhas na interação social, falhas de comunicação e interesses e comportamentos restritos e repetitivos. $\mathrm{O}$ aspecto essencial do texto refere-se à base biológica do transtorno, revelando interessantes correlações entre alguns sintomas do autismo e características neurobiológicas observadas pela própria autora em suas pesquisas anteriores.

A autora, doutora em embriologia e professora de ginecologia e obstetrícia da Universidade de Rochester, iniciou suas investigações após ter-se chocado com uma possível conexão entre a droga talidomida e a origem do autismo. Essa importante 
questão surgiu após ter assistido a uma conferência científica sobre defeitos de nascença, quando dois pediatras oftalmologistas apresentaram seus estudos sobre problemas de motilidade ocular em vítimas da talidomida. Os resultados revelaram que $5 \%$ das vítimas da talidomida tinham autismo, taxa aproximadamente 30 vezes maior que a encontrada na população geral. Todos os sujeitos dessa pesquisa apresentaram algumas das malformações próprias da talidomida e disfunções neurológicas dos músculos faciais e oculares. O tálamo cerebral tem sido a região mais implicada nestes estudos, não somente quanto às causas primárias dos sintomas relacionados à desordem, mas também aos efeitos secundários que uma lesão no tálamo poderia refletir no desenvolvimento de outras regiões cerebrais, inclusive as de nível superior, como o córtex cerebral e o hipocampo.

O texto indica que uma outra contribuição proporcionada pelos estudos dos efeitos dessa droga foi a observação de que a maioria das vítimas da talidomida com autismo tinham anormalidade na parte externa de suas orelhas, mas nenhuma malformação nos braços ou pernas. Considerando dados embriológicos, a autora destacou que os neurônios motores dos nervos cranianos se desenvolvem ao mesmo tempo que as orelhas externas e que esses sujeitos tinham sido malformados entre 20 a 24 dias após a concepção, indicando que o autismo também pode se originar nesse período. A partir dessas observações, a autora elaborou hipóteses que movimentaram suas pesquisas.

A revisão discute a relevância estatística da hereditariedade das desordens, que tem mostrado que o autismo aparece com maior freqüência entre membros de uma mesma família, embora não em uma seqüência clara e lógica. Parentes de pessoas com autismo têm uma chance de 3 a $8 \%$ de serem diagnosticadas com a mesma desordem. No entanto, estes dados não atingem os $50 \%$ de chance que poderia caracterizar uma doença genética causada por uma única mutação dominante ou os $25 \%$ que caracterizariam uma mutação recessiva. Variantes de muitos genes contribuem para essas especulações, embora os fatores genéticos não se expressem totalmente nos parentes que tenham alguns genes variantes ligados ao autismo. Estudos com gêmeos monozigóticos também questionaram o determinismo genético. No caso, se os fatores hereditários fossem lineares, gêmeos monozigóticos - com os mesmos genes - teriam $100 \%$ de chance de receber o mesmo diagnóstico, sendo que, na realidade, um dos pares tem apenas 60\% de chance de ser diagnosticado com a mesma desordem. Da mesma forma, o texto também levanta questões sobre o determinismo ambiental.

Em sua pesquisa, a autora e seu grupo examinaram o tálamo cerebral de um cadáver de uma jovem que tinha autismo sem causa conhecida, e observaram a ausência quase total do núcleo facial e da oliva superior. Também foi observado que as medidas antero-posteriores estavam muito reduzidas no tálamo cerebral. A autora deixou clara sua surpresa ao encontrar correspondências entre este último 
dado e os cérebros anormais de ratos transgênicos, nos quais havia encontrado este mesmo padrão de encurtamento em um estudo anterior. Deste modo, a autora constatou que a talidomida, e nenhum dos fatores do meio associados ao autismo, teria alterado o cérebro desses ratos, mas a eliminação da função de um gene, cujo nome é HOXA I e é ativado na tálamo cerebral no mesmo período em que os primeiros neurônios estão se formando e nos quais a talidomida esteve associada ao autismo. Esse achado inaugurou uma importante fase das investigações da autora e de seu grupo, que se iniciou pelo estudo da prevalência dos alelos variantes do HOXA I, a partir de amostras de sangue de pessoas com autismo e de sujeitos do grupo controle. Os resultados mostraram que a taxa do alelo variante entre pessoas com autismo era muito maior do que a taxa entre seus familiares que não a apresentavam e entre as pessoas não relacionadas também sem o autismo. Em aproximadamente $60 \%$ das pessoas com autismo o alelo não está presente, denunciando o fato de que outros fatores, genéticos ou não, podem contribuir para aumentar ou até mesmo diminuir o risco para a desordem. A cada estudo, a autora pondera a consistência dos resultados encontrados, mostrando, então, o percurso da ciência em uma área densa cujos dados estatísticos freqüentemente podem ter duas faces e que, no entanto, denunciam que a predisposição genética é relativa. Porém, a autora encerra seu texto sugerindo que pesquisadores insistam em testes genéticos, como, por exemplo, transferindo os alelos relacionados com o autismo para ratos que devem ser expostos a substâncias que aumentam o risco do autismo, como o etanol ou doenças como a rubéola, para investigar a interação entre fatores do meio e a hereditariedade.

Pode-se inferir que o autismo é uma síndrome multifatorial na qual estão envolvidos fenômenos genéticos e do meio-ambiente, em intensidade variáveis para cada caso. 
“Recidivas en intentos de suicidio: ¿un perfil específico?” S. R. Doblado Acta Psiquiatrica y Psicologica de America Latina, 2000, 46(1): 51-59. Resenhado por: Fernando Cano

\section{Haveria um perfil específico nas recidivas de tentativa de suicídio em zonas rurais?}

O autor deste interessante trabalho publicado na Acta Psiquiatrica $y$ Psicologica de America Latina é psiquiatra e faz parte da unidade de psiquiatria do hospital geral de Osuna, em Sevilha, na Espanha. Ele coloca, inicialmente, a preocupação com o aumento das taxas de tentativas de suicídio em todo o mundo, assim como na Espanha. Mostra que houve um aumento das incidências em todo o território nacional nas décadas de 80, principalmente nas grandes capitais.

A O.M.S. coordenou recentemente na Europa um estudo sobre as tentativas de suicídio ou parasuicídios (the WHO-EURO Multicentre Study on parasuicide), que tinha dois objetivos fundamentais: descrever os padrões epidemiológicos e tentar identificar fatores de risco, sociais e pessoais, que pudessem prever as condutas suicidas futuras. O autor faz, então, uma revisão da literatura internacional, trazendo os aspectos principais encontrados quanto às recidivas em tentativas de suicídios. Dá destaque ao abuso de substâncias, aos fatores socioeconômicos, aos diversos quadros psicopatológicos (desequilíbrios familiares, abuso de substâncias, transtornos de personalidades, antecedentes pessoais de tratamento psiquiátrico, antecedentes delitivos-sociopáticos) e ao fato de as recidivas se darem preferencialmente no ano seguinte após a primeira tentativa.

O trabalho realizado pelo autor espanhol é prospectivo, com pacientes que tentaram o suicídio pela segunda vez. Tenta, com isso, identificar nas recidivas fatores que previssem tentativas futuras. Dezoito casos de primeira recidiva de tentativa de suicídio são avaliados e comparados com setenta e um casos de uma primeira e única tentativa. A taxa de recidiva é de 20,2\%. Foram investigados como possíveis fatores implicados nas recidivas: o sexo, a impulsividade, enfermidades somáticas crônicas, antecedentes psiquiátricos, métodos farmacológicos, possibilidade de ajuda- 
resgate, crítica posterior à tentativa, diagnóstico psiquiátrico, tipo de fármacos utilizados, métodos não farmacológicos, grupo etário e gravidade clínica global. No perfil de recidiva foram encontradas diferenças estatisticamente significativas nos fatores: antecedentes psiquiátricos, sempre presentes; tipo de fármacos utilizados (psicofármacos mais potentes como antidepressivos heterocíclicos); e gravidade clínica maior quando da chegada ao serviço médico. O autor entende que um desenho mais detalhado, principalmente quanto às condições sociais e psicopatológicas dos pacientes podem trazer, em trabalhos futuros, mais clareza quanto aos possíveis marcadores de risco de recidivas.

O autor não encontrou na literatura trabalhos com indivíduos apresentando características sociodemográficas similares às dos que ele próprio estudou, ou seja, habitantes de zona rural, fundamentalmente agrária. O autor propõe que, no futuro, sejam feitos estudos similares também em zonas rurais, para que se tenha uma idéia mais clara das possíveis diferenças entre as condutas parasuicidas nas zonas rurais e urbanas, já que na literatura não faltam trabalhos desse tipo nas grandes cidades. Pensa que seria interessante se isso fosse feito aqui na América Latina, dadas as semelhanças com seu país.

Conclui, portanto, não existirem sinais clínicos prévios significativos nas recidivas, salvo os antecedentes psiquiátricos. A prevenção, portanto, é difícil por não existirem claros marcadores epidemiológicos de recidiva. Na prática, o seguimento cuidadoso dos pacientes com antecedentes de uma tentativa prévia parece ser a única medida viável. Deixa assinalado, porém, a importância de se fazerem novos estudos considerando especificamente os fatores sociodemográficos. 